\title{
Breeding Temperate Japonica Rice Varieties Adaptable to Tropical Regions: Progress and Prospects
}

\author{
Myrish Pacleb ${ }^{1}$, O-Young Jeong ${ }^{2}$, Jeom-Sig Lee ${ }^{2}$, Thelma Padolina ${ }^{3}$, Rustum Braceros ${ }^{3}$, Lenie Pautin ${ }^{3}$, \\ Gideon Torollo ${ }^{1}$, Elbert E. Sana ${ }^{4}$, Jesson Y. Del-Amen ${ }^{5}$, Man-Kee Baek ${ }^{2}$, Sumin Jo ${ }^{2}$, Woong-Jo Hyun ${ }^{2}$, \\ Hyun-Su Park ${ }^{2}$, Jong-Min Jeong ${ }^{2}$, Ji-Youn Lee ${ }^{2}$, Jun-Hyeon Cho ${ }^{2}$, Jeong-Heui Lee ${ }^{2}$, Sais-Beul Lee ${ }^{2}$, \\ Il-Ryong Choi ${ }^{1}$, Sung-Ryul Kim ${ }^{1}$, Jae-Sung Lee ${ }^{1}{ }^{\mathbb{D}}$, Nese Sreenivasulu ${ }^{1}{ }^{1}$, Jong-Cheol Ko ${ }^{2}$, Joum-Ho Lee ${ }^{2}$, \\ Byeong-Ju Kim ${ }^{2}$, Ki-Young Kim ${ }^{2}$ and Dong-Soo Park ${ }^{1,2, *(D)}$
}

Citation: Pacleb, M.; Jeong, O.-Y.; Lee, J.-S.; Padolina, T.; Braceros, R.; Pautin, L.; Torollo, G.; Sana, E.E.; Del-Amen, J.Y.; Baek, M.-K.; et al. Breeding Temperate Japonica Rice Varieties Adaptable to Tropical Regions: Progress and Prospects. Agronomy 2021, 11, 2253. https:// doi.org/10.3390/agronomy11112253

Academic Editors: Margarita A. Vishnyakova, Eric J. Bishop von Wettberg and Maria G. Samsonova

Received: 5 October 2021

Accepted: 5 November 2021

Published: 8 November 2021

Publisher's Note: MDPI stays neutral with regard to jurisdictional claims in published maps and institutional affiliations.

Copyright: (c) 2021 by the authors. Licensee MDPI, Basel, Switzerland. This article is an open access article distributed under the terms and conditions of the Creative Commons Attribution (CC BY) license (https:// creativecommons.org/licenses/by/ $4.0 /)$.
1 International Rice Research Institute, Los Baños 4031, Philippines; M.Pacleb@irri.org (M.P.); g.torollo@irri.org (G.T.); I.Choi@irri.org (I.-R.C.); s.r.kim@irri.org (S.-R.K.); JS.Lee@irri.org (J.-S.L.); n.sreenivasulu@irri.org (N.S.)

2 National Institute of Crop Science, Rural Development Administration, Jeonju 55365, Korea; joyoung@korea.kr (O.-Y.J.); leejsyr@korea.kr (J.-S.L.); baekmg@korea.kr (M.-K.B.); tnals88319@korea.kr (S.J.); onlybio@korea.kr (W.-J.H.); mayoe@korea.kr (H.-S.P.); jjm0820@korea.kr (J.-M.J.); minitia@korea.kr (J.-Y.L.); hy4779@korea.kr (J.-H.C.); lejehe@korea.kr (J.-H.L.); pappler@korea.kr (S.-B.L.); okjc317@korea.kr (J.-C.K.); ppjhlee4093@korea.kr (J.-H.L.); kimbj1713@korea.kr (B.-J.K.); gold5501@korea.kr (K.-Y.K.)

3 Philippine Rice Research Institute, Munoz 3119, Philippines; thelmapadolina@yahoo.com (T.P.); rcbraceros@gmail.com (R.B.); leniepautin2016@gmail.com (L.P.)

4 College of Agriculture, Nueva Vizcaya State University, Bayombong 3700, Philippines; tombysana@yahoo.com

5 College of Agriculture, Benguet State University, Benguet 2601, Philippines; jydelamen@gmail.com

* Correspondence: parkds9709@korea.kr

\begin{abstract}
Temperate japonica rice is mainly cultivated in temperate regions. Many temperate japonica varieties have a superior grain quality that is preferred in Northeast Asian countries such as Japan, Korea, and China. The changes in consumers' preferences in Southeast Asia and Western countries has contributed to increasing the demand for temperate japonica. Most temperate japonica varieties developed in temperate regions typically exhibit extra-early flowering under the short-day conditions in the tropics, which usually results in severely reduced yields. Since 1992, we have been developing temperate japonica varieties that can adapt to tropical environments to meet the increasing demand for temperate japonica rice, having released six varieties in the Philippines. Especially, the yield of one of the temperate japonica varieties, Japonica 7, was comparable to the yields of leading indica varieties in the Philippines. Here, we discuss the current breeding initiatives and future plans for the development of tropical-region-bred temperate japonica rice.
\end{abstract}

Keywords: Oryza sativa L.; temperate japonica; tropical region; adaption; breeding

\section{Introduction}

Japonica rice, a subspecies of Oryza sativa L., can thrive in tropical and temperate zones; hence, it can be divided into two subgroups: temperate japonica and tropical japonica [1]. Tropical japonica is cultivated in Southeast Asian countries such as the Philippines and Indonesia, while temperate japonica is mostly grown in North-East Asian countries such as Japan, Korea, and China, where the seasonal changes in climate temperature are distinct. Globally, temperate japonica is more produced and consumed than tropical japonica [2]. Due to the unique attributes of temperate japonica varieties such as their sticky texture, they are often classified as special-purpose rice in the regions where indica rice is predominantly consumed or rice is not the primary staple food [3]. Many temperate japonica rice varieties are valued for their sticky texture and high grain quality that are distinct from those of indica. However, due to the poor adaptability of many temperate japonica rice plants to 
tropical environments, the production of temperate japonica rice has been very limited in the Southeast Asian countries. Sustaining an adequate supply is becoming more challenging mainly due to factors such as the low yield potential of japonica varieties and susceptibility to pests and diseases under tropical environments. Although temperate japonica rice has small and very specialized markets in Southeast Asia, the demand for temperate japonica varieties is increasing and it has great potential for realizing higher income returns to farmers in the region.

\section{Progress of Temperate Japonica Rice Adaptable to Tropical Regions}

Facing the increasing demand for japonica varieties in the tropics, the Rural Development Administration (RDA) of the Korean government and International Rice Research Institute (IRRI) initiated the Germplasm Utilization Value Added (GUVA) project from 1992 in cooperation with the Philippine Rice Research Institute (PhilRice), with a budget scale of USD 150,000 every year. The aim of the GUVA project is to develop japonica varieties with high yield potential and desirable agronomic characteristics that are adaptable to the tropics. We used japonica varieties from South Korea as the starting materials for line development. However, the photosensitivity of many temperate japonica rice plants was the major bottleneck in the selection of suitable plant base materials for field tests. Under the short-day conditions in the tropics, many temperate japonica varieties typically exhibit extraearly flowering ( $\sim 5$ days after seeding) compared to indica rice plants (around 75 days after seeding) [3]. The extreme early flowering of temperate japonica in the tropics results in a reduced yield due to a reduction in biomass and poor panicle development. Kim et al. [4] reported that the yields of the Korean temperate japonica varieties showing extra-early heading in the tropical region were 0.6 to 1.4 ton/ha, while those in Korea located in the temperate region were 7 to 10 ton/ha. The interplay of flowering factors under different photoperiodic conditions limits the speed of japonica rice's adaptation to the tropics [5], and it was one of the main challenges of temperate japonica rice breeding in the tropics. The transition from the long-day conditions in the temperate areas to the short-day conditions in the tropics appeared to be the cause of stunted growth, weak tillers, small panicles, and premature headings of the temperate japonica rice in the tropics [5]. Fortunately, early GUVA scientists found that some japonica rice germplasm sources such as Jinmibyeo showed delayed heading [4] which were deployed in the GUVA breeding program.

Despite the difficulty in finding genetic materials with a suitable heading property and resistance to biotic stresses in the tropics, the very first successful breed of temperate japonica rice, variety MS 11 (Maligaya Special 11), was released in 2008 in the Philippines. MS 11 was the product of a cross between two Korean japonica varieties, Jimnibeyo, showing delayed heading under the short-day condition, and Cheolweon 46, which is a japonica rice resistant to diseases and pests prevalent in the Philippines. MS 11 is a semi-dwarf $(90 \mathrm{~cm})$ and earlymaturing (112 days) variety, and has short, round-shaped grains, possessed low amylose content $(15.5 \%)$, and a low gelatinization temperature, which are the typical characteristics of japonica rice. Multi-location trials demonstrated that MS 11 yielded an average of 4.9 ton/ha with $70 \%$ premium milling and $60 \%$ head rice recovery rates [6]. In 2009, IRRI 152 (NSIC Rc220), locally known as Japonica 1, was released in the Philippines (https: / / nsic.buplant.da.gov.ph/, accessed on 13 September 2021). This variety demonstrated attributes comparable to those of MS 11, and its yield was approximately $25 \%$ higher than that of MS 11 based on multi-location trials. In 2010, MS 11 and Japonica 1 were approved for large-scale planting by the National Seed Industry Council (NSIC) of the Philippines and officially handed to farmers of Bohol for commercial cultivation. As of 2021, four more japonica varieties, namely, Japonica 2 (https:/ / nsic.buplant.da.gov.ph/, accessed on 13 September 2021), Japonica 6 [7], Japonica 7 [8], and Cordillera 4 [9], had been developed (Tables 1-3). These varieties were also recommended to be released in the Philippines based on the National Cooperative Test (NCT) that evaluates the yield performance, grain quality (milling traits and physical properties) and reactions to pests and diseases of candidate varieties for four consecutive seasons under multiple environments to decide whether to 
accept or reject a variety. Once the varieties were developed, they were evaluated through the farmer participatory varietal selection (PVS) process as a part of the participatory technology transfer of IRRI.

Table 1. Six temperate japonica rice varieties developed from the GUVA project.

\begin{tabular}{|c|c|c|c|c|c|}
\hline Variety & Release Name & IRRI Designation & Parentage & Year Registered & Reference \\
\hline MS11* & NSIC Rc 170 SR & IRRI 142 & $\begin{array}{c}\text { Jinmibyeo/ } \\
\text { Cheolweon } 46\end{array}$ & 2008 & Jeong et al. [6] \\
\hline Japonica 1 & NSIC Rc 220 SR & IRRI 152 & $\begin{array}{l}\text { IR77863-95-2- } \\
\text { 3/HR15490-34 }\end{array}$ & 2009 & $\begin{array}{c}\text { https: } \\
\text { //nsic.buplant.da.gov.ph/, } \\
\text { accessed on } \\
\text { 13 September } 2021 \\
\text { https: }\end{array}$ \\
\hline Japonica 2 & NSIC Rc 242 SR & IRRI 157 & $\begin{array}{c}\text { IR80091-46-2- } \\
\text { 1/IR71663-14-2-3-5 }\end{array}$ & 2011 & $\begin{array}{c}\text { //nsic.buplant.da.gov.ph/, } \\
\text { accessed on } \\
\text { 13 September } 2021\end{array}$ \\
\hline Japonica 6 & NSIC Rc 484 SR & IRRI 202 & $\begin{array}{c}\text { MS } \\
\text { 11/IR86743-2B-1-4 }\end{array}$ & 2017 & Jeong et al. [7] \\
\hline Cordillera 4 & NSIC Rc 566 SR & IRRI 232 & $\begin{array}{c}\text { Jinmibyeo/SR18977- } \\
\text { 2-7-2-TB-1 }\end{array}$ & 2019 & Jeong et al. [9] \\
\hline Japonica 7 & NSIC Rc 584 SR & IRRI 236 & $\begin{array}{c}\text { Japonica } \\
\text { 2/IR11K233 }\end{array}$ & 2019 & Jeong et al. [8] \\
\hline
\end{tabular}

${ }^{*}$ Local name of MS 11 in Korea is Asemi.

Table 2. Main agronomic traits of the temperate japonica rice varieties based on the NCT.

\begin{tabular}{|c|c|c|c|c|c|c|}
\hline \multirow{2}{*}{ Variety * } & \multirow{2}{*}{$\begin{array}{l}\text { Culm Length } \\
\text { (cm) }\end{array}$} & \multirow{2}{*}{$\begin{array}{l}\text { Days to } \\
\text { Maturity }\end{array}$} & \multicolumn{2}{|c|}{ Yield (t/ha) } & \multirow{2}{*}{$\begin{array}{c}\text { Milling } \\
\text { Recovery (\%) }\end{array}$} & \multirow{2}{*}{$\begin{array}{c}\text { Eating } \\
\text { Quality }\end{array}$} \\
\hline & & & Variety & Check Variety ** & & \\
\hline MS11 & 90 & 112 & 4.9 & $\begin{array}{c}4.5 \\
\text { (IR72) }\end{array}$ & 70.5 & Soft \\
\hline Japonica 1 & 89 & 109 & 2.8 & $\begin{array}{c}2.3 \\
(\mathrm{MS} 11)\end{array}$ & 64.7 & Soft \\
\hline Japonica 2 & 94 & 109 & 3.7 & $\begin{array}{c}3.0 \\
\text { (MS11) }\end{array}$ & 63.0 & Soft \\
\hline Japonica 6 & 87 & 121 & 3.6 & $\begin{array}{c}2.6 \\
\text { (MS11) }\end{array}$ & 73.0 & Medium \\
\hline Cordillera $4^{* * *}$ & 77 & 145 & 3.1 & $\begin{array}{c}2.5 \\
\text { (PSB Rc 96) }\end{array}$ & 73.0 & Soft \\
\hline Japonica 7 & 91 & 111 & 3.0 & $\begin{array}{c}2.6 \\
\text { (MS11) }\end{array}$ & 69.0 & Soft \\
\hline
\end{tabular}

* All data are based on the NCT (National Cooperative Test) in the Philippines with different years/regions for each variety; ${ }^{* *}$ Yield and the name of check varieties; ${ }^{* * *}$ NCT for Cordillera 4 was conducted in cold and elevated regions in the Philippines.

Table 3. Responses to major biotic stresses of the temperate japonica rice varieties based on the NCT.

\begin{tabular}{|c|c|c|c|c|c|c|}
\hline Variety * & Blast & Bacterial Leaf Blight & Tungro Disease & Stem Borer & $\begin{array}{c}\text { Brown } \\
\text { Planthopper }\end{array}$ & $\begin{array}{c}\text { Green } \\
\text { Leafhopper }\end{array}$ \\
\hline MS11 & $\mathrm{R}^{* *}$ & I & I & I & $S$ & $S$ \\
\hline Japonica 1 & $S$ & I & S & $\mathrm{I}$ & $\mathrm{I}$ & $S$ \\
\hline Japonica 2 & I & I & $S$ & MS & MS & MS \\
\hline Japonica 6 & I & I & S & I & S & $S$ \\
\hline Cordillera 4 & I & S & S & $\mathrm{R}$ & I & MR \\
\hline Japonica 7 & I & I & $S$ & $\mathrm{R}$ & I & I \\
\hline
\end{tabular}

${ }^{*}$ All data are based on the NCT (National Cooperative Test) in the Philippines with different years/regions for each variety; ** $\mathrm{R}-$ resistant; MR—moderately resistant; I—intermediate; MS—moderately susceptible; S—susceptible.

According to Kim et al. [4], the rice germplasm accessions originating from the tropi$\mathrm{cal} /$ subtropical regions harbor the non-functional alleles of Hd1 associated with heading, 
and all 12 temperate japonica varieties and breeding lines that were developed under the GUVA project possessed the loss-of-function alleles of $H d 1$, which are not common in temperate japonica varieties. A phylogenetic analysis using 2918 SNP data points revealed that the genome statuses of the 12 breeding lines were very similar to those of the Korean temperate japonica varieties. These results indicate that the functional Hd1 alleles of temperate japonica varieties induced extremely early flowering in the tropics and the non-functional Hd1 alleles brought about the adaptation of temperate japonica rice to tropical regions. Bombay et al. [5] also suggested that a non-functional $H d 1$ allele was critical for the tropical adaptation of temperate japonica rice, since it delays the heading date, which is essential for prolonging the vegetative state and achieving optimum biomass, an increased spikelet number, and a high grain-filling capacity.

\section{Breakthrough in Yield with the New Variety, Japonica 7}

The initial japonica varieties developed under the GUVA project clearly underperformed with respect to the indica group in terms of yield and stability under the tropical environment compared to recent leading indica varieties. On the contrary, the yields of the most recent variety, Japonica 7, were observed to be similar to or higher than those of high-yielding indica varieties such as NSIC Rc 222 and NSIC Rc 238 in the field trials at IRRI $\left(14.2^{\circ} \mathrm{N}, 121.2^{\circ} \mathrm{E}\right)$ and Philippine Rice Research Institute $\left(15.3^{\circ} \mathrm{N}, 121.0^{\circ} \mathrm{E}\right)$ in the 2021 dry season (Table 4 ).

Table 4. Yields of temperate japonica rice varieties developed under the GUVA project and leading indica varieties in the 2021 dry season.

\begin{tabular}{|c|c|c|c|c|}
\hline \multirow{3}{*}{ Variety } & \multicolumn{4}{|c|}{ Yield (Rough Rice) } \\
\hline & \multicolumn{2}{|c|}{ IRRI } & \multicolumn{2}{|c|}{ PhilRice-CES * } \\
\hline & Ton/Ha & $\%$ ** & Ton/Ha & $\% * *$ \\
\hline MS 11 & 5.4 & 79 & 5.8 & 73 \\
\hline Japonica 1 & 6.1 & 90 & 5.3 & 66 \\
\hline Japonica 2 & 5.4 & 79 & 5.6 & 70 \\
\hline Japonica 6 & 7.1 & 104 & 6.0 & 75 \\
\hline Japonica 7 & 7.0 & 103 & 8.8 & 110 \\
\hline NSIC Rc 222 (indica) *** & 6.8 & 100 & 8.0 & 100 \\
\hline NSIC Rc 238 (indica) *** & 6.8 & 100 & 6.3 & 79 \\
\hline $\operatorname{LSD}(0.05)^{* * * *}$ & 0.6 & - & 1.3 & - \\
\hline
\end{tabular}

*Central Experiment Station, Philippine Rice Research Institute located in Nueva Ecija, Philippines; ${ }^{* *}$ Relative yield level when the yield of NSIC Rc 222 is considered as $100 \%$; ${ }^{* * *}$ NSIC Rc 222 and NSIC Rc 238 are the leading varieties in the Philippines; ${ }^{* * * *}$ Least significant difference.

Japonica 7 also showed intermediate reactions or resistance to bacterial leaf blight (BLB), stem borer, brown planthopper (BPH), and green leafhopper in the NCT (Table 3). Japonica 7 was regarded as susceptible to tungro disease in the NCT (Table 3); however, this variety showed moderate field resistance against tungro disease at IRRI in the 2020 wet season (Figure 1). 


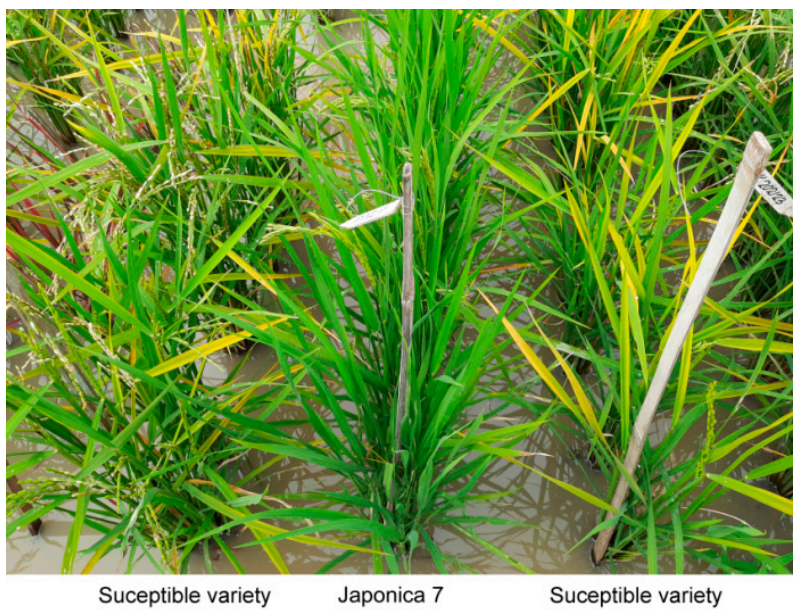

Figure 1. Field resistance to tungro disease of Japonica 7 in the 2020 wet season at IRRI.

As mentioned above, MS 11 and Japonica 7 showed moderate resistance to tungro disease. Rice tungro spherical virus (RTSV) is one of the viruses causing tungro disease [9]. The resistance to RTSV is associated with the allele types of the gene encoding eukaryotic translation initiation factor 4 gamma (EIF4G, LOC_Os07g3690) [10]. To examine the presence of the resistance allele of EIF4G in the six GUVA varieties, EIF4G in these varieties was partially sequenced. The partial sequences of EIF4G showed that MS 11 and Japonica 7 possess the resistance allele of EIF4G (Table 5), which is consistent with the moderate resistance to tungro disease observed in these varieties.

Table 5. Sequences of the 30-bp region (3163 to 3192) of EIF4G (LOC_Os07g3690) in the six temperate japonica rice varieties developed under the GUVA project and an RTSV-susceptible variety, Nipponbare.

\begin{tabular}{ccc}
\hline Variety & Position in EIF4G $($ LOC_Os07g3690) & Allele Type \\
\hline Nipponbare & 3163 GCCGGAAAGTCTTATGTTGTTGATCACCCA 3192 & Susceptible \\
MS 11 & GCCGTAAAGTCTTATGTTGTTGATCACCCA & Resistant \\
Japonica 1 & GCCGGAAAGTCTTATGTTGTTGATCACCCA & Susceptible \\
Japonica 2 & GCCGGAAAGTCTTATGTTGTTGATCACCCA & Susceptible \\
Japonica 6 & GCCGGAAAGTCTTATGTTGTTGATCACCCA & Susceptible \\
Japonica 7 & GCCGTAAAGTCTTATGTTGTTGATCACCCA & Resistant \\
Cordillera 4 & GCCGGAAAGTCTTATGTTGTTGATCACCCA & Susceptible \\
\hline
\end{tabular}

\section{Challenges and Breeding Initiatives}

The heading date and yield of the GUVA japonica varieties are much improved, but there is still a gap in the yield of the temperate japonica varieties between the tropics and the temperate region. The Ehd1 gene, encoding a B-type response regulator protein, promotes the expression of florigen genes such as Hd3a and RFT1 under both short-day and long-day conditions [11]. The transfer of the non-functional allele of Ehd1 into the GUVA varieties may delay their heading dates and enhance their yields. GN1a [12] and OsSPL14/WFP [13] control the grain number per panicle, and SCM2 governs the grain number per panicle and strong culm [14]. The yield-related alleles of these genes, which are usually absent in temperate japonica varieties, need to be tested in the GUVA varieties to see their effects on yield enhancement. Whenever possible, the marker-based selection of these genes is desirable to precisely transfer only the target genes/alleles ( $<100 \mathrm{~kb}$ size $)$ from indica donors to japonica backgrounds to keep the original characteristics of the elite japonica varieties and to avoid undesired traits in the final breeding products such as poor fertility.

Besides the traits for the heading date and yield, the development of temperate japonica rice in the tropics requires the improvement of disease and pest resistance and grain quality. Enhancing the tolerance to pests and diseases in new varieties is one of the fundamental 
goals of the current breeding program for temperate japonica rice in the tropics. Among various biotic stresses, BPH, BLB, tungro, and blast are the most common that hamper the growth performance of temperate japonica varieties under the tropical environment. Genes associated with resistance to blast (Pita), BLB (xa5), and BPH (BPH32) were already incorporated into high-yielding indica varieties such as NSIC Rc 222 and NSIC Rc 238 (Table 6). The SNP-based allele typing of these three resistance genes in the six released GUVA japonica varieties showed out that none of the six varieties have these resistance genes (Table 6).

Table 6. Allele types for some of biotic-stress-resistance genes for six temperate japonica rice varieties developed from the GUVA project.

\begin{tabular}{|c|c|c|c|}
\hline \multirow{2}{*}{ Variety } & \multicolumn{3}{|c|}{ Allele Type of Resistance Gene * } \\
\hline & Blast (Pita) & BLB $(x a 5)$ & ВРН (ВРН32) \\
\hline MS 11 & S & $\mathrm{S}$ & S \\
\hline Japonica 1 & S & $\mathrm{S}$ & S \\
\hline Japonica 2 & S & S & S \\
\hline Japonica 6 & S & $\mathrm{S}$ & S \\
\hline Japonica 7 & S & $\mathrm{S}$ & S \\
\hline Cordillera 4 & $\mathrm{~S}$ & $\mathrm{~S}$ & S \\
\hline NSIC Rc 222 (indica) ** & $\mathrm{R}$ & $\mathrm{R}$ & $\mathrm{R}$ \\
\hline NSIC Rc 238 (indica) ** & $\mathrm{R}$ & $\mathrm{R}$ & $\mathrm{R}$ \\
\hline
\end{tabular}

The genotypic screening of 181 rice germplasm accessions revealed that only $4.1 \%$ of japonica accessions harbor the resistance allele type of Pita, whereas $83.5 \%$ of indica accessions have the resistance allele (Table 7). The frequencies of the resistance allele types for $x a 5$ and BPH 32 in temperate japonica and indica were similar to those for Pita (Table 7). These results suggest that many temperate japonica rice plants, which have been mostly cultivated in the temperate region, do not harbor important genes necessary to adapt to the tropical region. To develop disease- and insect-resistant japonica varieties for the tropics, the resistance alleles of these genes should be incorporated into future japonica breeding lines through the marker-assisted selection (MAS) of the resistance alleles and precise bioassays for the target pests and diseases.

Table 7. Number (percentage) of japonica and indica rice accessions harboring the resistance alleles of Pita, xa5, and BPH32 among 181 rice germplasm accessions.

\begin{tabular}{cccc}
\hline \multirow{2}{*}{ Subspecies } & \multicolumn{3}{c}{ Number (Percentage) of Rice Accessions Harboring Resistance Allele Type } \\
\cline { 2 - 4 } & Blast (Pita) & BLB $(x a 5)$ & BPH (BPH32) \\
\hline \multirow{3}{*}{ Japonica } & $4(4.1 \%)$ & $6(6.3 \%)$ & \\
(96) & Dongiinbyeo, & IR13K158, IR13K176 & $3(3.1 \%)$ \\
& IR13K187 & IR13K177, IR13K181 & IR13K187, IR18K1018 \\
Indica & IR18K1018, & IR13K187, IR18K1018 & \\
IR18K1028 & $71(83.5 \%)$ & & $52(61.1 \%)$ \\
\hline
\end{tabular}

Under the tropical environment, the grains of many temperate japonica germplasm accessions and many of our current temperate japonica breeding lines are prone to preharvest sprouting (PHS) and have short seed longevity and poor grain quality such as in exhibiting grain breakage and grain chalkiness under tropical climate conditions, especially during the wet season $[15,16]$ (Figure 2). Overcoming these limitations is critical because these usually cause significant reductions in grain quality and yield. 


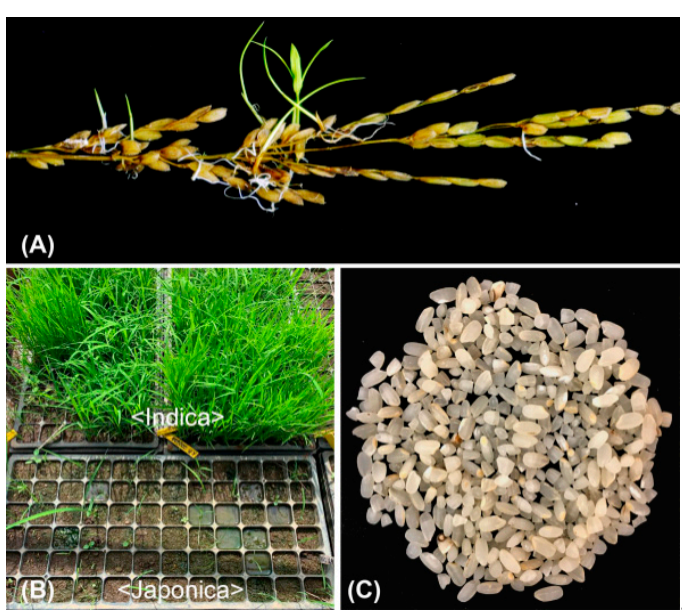

Figure 2. Inferior grain quality of temperate japonica rice under the tropical climate. (A) Pre-harvest sprouting, (B) short seed longevity, and (C) cracked milled rice.

PHS, the germination of seeds on panicles prior to harvest, often occurs under warm and humid weather conditions and due to unexpected weather events such as typhoons at the seed-maturity stage [17-19]. As compared with indica rice widely grown in the tropical region, temperate japonica rice varieties have adapted to cool and dry environments during the seed-ripening period; hence, they are vulnerable to PHS when cultivated under tropical climate conditions. Lee et al. [15] screened 48 japonica varieties cultivated in the temperate regions-California in the United States, Japan, and the Republic of Korea-and the mean PHS resistance of these japonica varieties was 39\%, whereas the control group composed of 24 indica varieties showed outstanding resistance, with a mean of $93 \%$. The Sdr4 locus on chromosome 7 involved in flavonoid biosynthesis and abscisic acid signaling pathways is responsible for the strong PHS resistance in indica rice varieties [20,21]. Japonica-derived loci on chromosome 1 and 4 associated with PHS resistance are related to plant-hormonemediated signaling pathways [15]. Breeding efforts to introgress the PHS-resistance loci into elite temperate japonica varieties are underway.

Seed longevity is a key trait for securing farmers' seed lots under hot and humid weather [22]. The loss of seed viability and vigor, especially under rapid climate change, leads to poor crop establishment and a low yield as well as reduced eating quality, which often result in serious economic losses. It is therefore necessary to improve the seed longevity of the GUVA lines using indica or aus resources having relatively high seed longevity [16,23-25]. Sasaki et al. [26] reported that TPP7, encoding a trehalose-6-phosphate phosphatase, in the $q L G-9$ locus on chromosome 9 controls the seed longevity of temperate japonica $\mathrm{x}$ indica rice near isogenic lines. Other seed-longevity genes identified through a genome-wide association analysis using the indica and aus rice panels from the 3000 Rice Genomes Project [27] are related to DNA repair and transcription, sugar metabolism and reactive-oxygen-species scavenging [28,29].

The head rice yield is the percentage of intact grains obtained from rough rice after the milling process. The head rice yield directly affects the income of rice farmers because the price of whole-grain rice is typically several times higher than that of broken grains. Rice milling is a multi-step process that includes hulling, milling, and separating whole kernels from broken ones. The cracking of rice kernels (or kernel fissuring) is one of the major problems in producing temperate japonica rice under the tropics. It reduces the market value, increases the ratio of broken rice during milling and cooking, and diminishes flavor [30]. Cracking often follows harvest delays due to unstable weather, heavy rain, or high air temperatures [31,32]. Several QTLs associated with kernel-cracking resistance were identified in japonica rice [33,34], indica rice [35], and wild rice [30]. DNA markers linked to QTLs associated with kernel-cracking resistance would facilitate the efficient selection 
of japonica rice breeding lines with kernel-cracking resistance without being significantly affected by harvesting and milling conditions.

\section{Conclusions and Future Work}

The goal of our endeavor described here is to develop temperate japonica varieties adapted to the tropical environment. The outcomes of our efforts not only can widen the potential market into which farmers in the tropical regions could tap, but also will provide competent genetic resources of temperate japonica rice ready for any drastic consequences of global warming. For the last 29 years, we have delivered six released varieties, which expanded the cultivation area for temperate japonica to tropical regions by introducing the non-functional allele of the $H d 1$ gene and resistance against some of the major diseases and pests to ensure high yield stability in the tropics.

Despite having overcome some of the prevalent problems encountered with temperate japonica rice in the tropical environment, temperate japonica varieties remain less popular in Southeast Asian countries. For now, the cultivation of japonica rice cultivars is still very limited. Furthermore, our initial varieties such as MS 11 or Japonica 1 are mostly cultivated in the region. Information on the performance of our recent cultivars in farmers' fields is still lacking. This is most probably due to multi-faceted problems associated with seed dissemination to seed producers and farmers, little access to more comprehensive data for the recent high-yielding varieties such as Japonica 7 , and the grain quality of temperate japonica varieties that may not meet farmers' preferences.

In addition, the following concerns still need to be addressed for the further development of temperate japonica varieties adaptable to the tropics: (1) enhancing yields in the wet season; (2) introducing resistance to biotic and abiotic stresses; and (3) improving grain quality by alleviating PHS, short seed longevity, and grain breakage.

Our future work will focus more on highly efficient molecular breeding based on accurate genetic information on high-impact QTLs/genes for yield stability and potential, enhanced resistance to biotic and abiotic stresses, and high grain quality in order to develop superior japonica rice varieties with improved adoption and enhanced genetic gain in tropical regions. This will be achieved by combining the conventional breeding process and new breeding tools such as trait genotyping for improved parental selection, markerand genomics-assisted breeding, and speed breeding.

Author Contributions: Conceptualization, D.-S.P. and I.-R.C.; Rice breeding, M.P., D.-S.P., O.-Y.J., J.-S.L. (Jeom-Sig Lee), T.P., R.B., L.P., G.T., E.E.S., J.Y.D.-A., M.-K.B., S.J., W.-J.H., H.-S.P., J.-M.J., J.-Y.L., J.-H.C. and J.-H.L. (Jeong-Heui Lee); Molecular genetic studies, M.P., S.-B.L., S.-R.K. and J.-S.L. (JaeSung Lee); Review and editing, I.-R.C., S.-R.K., J.-S.L. (Jae-Sung Lee) and N.S.; Project administration, J.-C.K., J.-H.L. (Joum-Ho Lee), B.-J.K. and K.-Y.K. All authors have read and agreed to the published version of the manuscript.

Funding: This work was conducted with the support of the "Cooperative Research Program for Agriculture Science \& Technology Development (Project title: The Germplasm Utilization for Value Added (GUVA) Traits of Japonica Rice (Phase II), Project No. PJ0121012021" Rural Development Administration, Republic of Korea, and "Temperate Rice Research Consortium (TRRC)".

Institutional Review Board Statement: Not applicable.

Informed Consent Statement: Not applicable.

Data Availability Statement: Not applicable.

Conflicts of Interest: The authors declare no conflict of interest. 


\section{References}

1. Wang, C.H.; Zheng, X.M.; Xu, Q.; Yuan, X.P.; Huang, L.; Zhou, H.F.; Wei, X.H.; Ge, S. Genetic diversity and classification of Oryza sativa with emphasis on Chinese rice germplasm. Heredity 2014, 112, 489-496. [CrossRef]

2. Changrong, Y.; Hengming, L.; Wei, D.; Jinwen, Z.; Yuran, X.; Anyu, G.; Yonggang, L.; Wei, N.; Shengli, S.; Hua, A.; et al. Genome-wide association study on agronomic traits of temperate japonica rice (Oryza sativa L.). Crop Breed. Appl. Biotechnol. 2020, 20, e22462011. [CrossRef]

3. Prisana, S.; Linnemann, A. Rice-eating quality among consumers in different rice grain preference countries. J. Sens. Stud. 2008, 23, 1-13.

4. Kim, S.R.; Torollo, G.; Yoon, M.R.; Kwak, J.; Lee, C.K.; Prahalada, G.D.; Choi, I.R.; Yeo, U.S.; Jeong, O.Y.; Jena, K.K.; et al. Loss-of-function alleles of heading date $1(\mathrm{Hd} 1)$ are associated with adaptation of temperate japonica rice plants to the tropical region. Front. Plant Sci. 2018, 871, 1-14. [CrossRef] [PubMed]

5. Bombay, M.; Lee, S.B.; Pacleb, M.; Jo, S.; Lee, J.Y.; Cho, J.H.; Lee, J.H.; Kang, J.W.; Kim, S.R.; Lee, J.S.; et al. Mapping of a Major QTL, $q H D 6-S D$ responsible for days to heading under natural short day conditions to develop rice varieties adaptable to tropical regions. J. Korean Soc. Int. Agric. 2021, 33, 161-169. (In Korean) [CrossRef]

6. Jeong, E.G.; Kang, K.H.; Hong, H.C.; Cho, Y.C.; Jung, O.Y.; Jeon, Y.H.; Chang, J.K.; Lee, J.H.; Won, Y.J.; Yang, U.H.; et al. A wide region of tropical Asia adaptable japonica rice 'Asemi'. J. Korean Soc. Int. Agric. 2019, 31, 76-81. (In Korean) [CrossRef]

7. Jeong, O.Y.; Torollo, G.; Bombay, M.; Baek, M.K.; Ahn, E.K.; Hyun, W.J.; Park, H.S.; Jeong, J.M.; Cho, J.H.; Lee, J.H.; et al. Adaptable tropical japonica high quality new rice cultivar 'Japonica 6'. J. Korean Soc. Int. Agric. 2019, 31, 249-254. (In Korean) [CrossRef]

8. Jeong, O.Y.; Lee, J.S.; Bombay, M.; Torollo, G.; Padolina, T.; Braceros, R.; Pautin, L.; Baek, M.K.; Ahn, E.K.; Hyun, W.J.; et al. A new high quality japonica rice cultivar 'Japonica 7' adaptable to tropical region. J Korean Soc. Int. Agric. 2020, 32, 151-157. (In Korean) [CrossRef]

9. Jeong, O.Y.; Lee, J.S.; Bombay, M.; Torollo, G.; Padolina, T.; Braceros, R.; Pautin, L.; Baek, M.K.; Ahn, E.K.; Hyun, W.J.; et al. A cold-tolerant japonica rice cultivar 'Cordillera 4' adaptable to the tropical mountainous region. J. Korean Soc. Int. Agric. 2021, 33, 119-124. (In Korean) [CrossRef]

10. Lee, J.H.; Muhsin, M.; Atienza, G.A.; Kwak, D.Y.; Kim, S.M.; Leon, T.B.D.; Angeles, E.R.; Coloquio, E.; Kondoh, H.; Satoh, K.; et al. Single nucleotide polymorphisms in a gene for translation initiation factor (eIF4G) of rice (Oryza sativa) associated with resistance to rice tungro spherical virus. Mol. Plant-Microbe Interact. 2010, 23, 29-38. [CrossRef]

11. Doi, K.; Izawa, T.; Fuse, T.; Yamanouchi, U.; Kubo, T.; Shimatani, Z.; Yano, M.; Yoshimura, A. Ehd1, a B-type response regulator in rice, confers short-day promotion of flowering and controls FT-like gene expression independently of Hd1. Genes Dev. 2004, 18, 926-936. [CrossRef] [PubMed]

12. Ashikari, M.; Sakakibara, H.; Lin, S.; Yamamoto, T.; Takashi, T.; Nishimura, A.; Angeles, E.R.; Qian, Q.; Kitano, H.; Matsuoka, M. Cytokinin oxidase regulates rice grain production. Science 2005, 309, 741-745. [CrossRef] [PubMed]

13. Miura, K.; Ikeda, M.; Matsubara, A.; Song, X.J.; Ito, M.; Asano, K.; Matsuoka, M.; Kitano, H.; Ashikari, M. OsSPL14 promotes panicle branching and higher grain productivity in rice. Nat. Genet. 2010, 42, 545-549. [CrossRef] [PubMed]

14. Ookawa, T.; Hobo, T.; Yano, M.; Murata, K.; Ando, T.; Miura, H.; Asano, K.; Ochiai, Y.; Ikeda, M.; Nishitani, R.; et al. New approach for rice improvement using a pleiotropic QTL gene for lodging resistance and yield. Nat. Commun. $2010,1,132$. [CrossRef] [PubMed]

15. Lee, J.S.; Chebotarov, D.; McNally, K.L.; Pede, V.; Setiyono, T.D.; Raquid, R.; Hyun, W.J.; Jeung, J.U.; Kohli, A.; Mo, Y. Novel sources of pre-harvest sprouting resistance for japonica rice improvement. Plants 2021, 10, 1709. [CrossRef]

16. Lee, J.S.; Kwak, J.; Yoon, M.; Lee, J.; Hay, F. Contrasting tocol ratios associated with seed longevity in rice variety groups. Seed Sci. Res. 2017, 27, 273-280. [CrossRef]

17. Tao, L.; Wang, X.; Tan, H.; Chen, H.; Yang, C.; Zhuang, J.; Zheng, K. Physiological analysis on pre-harvest sprouting in recombinant inbred rice lines. Front. Agric. China 2007, 1, 24-29. [CrossRef]

18. Fang, J.; Chu, C. Abscisic acid and the pre-harvest sprouting in cereals. Plant Signal Behav. 2008, 3, 1046-1048. [CrossRef]

19. Barnard, A.; Smith, M.F. The effect of rainfall and temperature on the preharvest sprouting tolerance of winter wheat in the dryland production areas of the Free State Province. Field Crops Res. 2009, 112, 158-164. [CrossRef]

20. Sugimoto, K.; Takeuchi, Y.; Ebana, K.; Miyao, A.; Hirochika, H.; Hara, H.; Ishiyama, K.; Kobayashi, M.; Ban, Y.; Hattori, T.; et al. Molecular cloning of Sdr4, a regulator involved in seed dormancy and domestication of rice. Proc. Natl. Acad. Sci. USA 2010, 107, 5792-5797. [CrossRef]

21. Gu, X.Y.; Foley, M.E.; Horvath, D.P.; Anderson, J.V.; Feng, J.H.; Zhang, L.H.; Mowry, C.R.; Ye, H.; Suttle, J.V.; Kadowaki, K.I.; et al. Association between seed dormancy and pericarp color is controlled by a pleiotropic gene that regulates abscisic acid and flavonoid synthesis in weedy red rice. Genetics 2011, 189, 1515-1524. [CrossRef]

22. Rency, R.; Kohli, A.; Reinke, R.; Dionisio-Sese, M.; Kwak, J.; Chebotarov, D.; Mo, Y.; Lee, J.S. Genetic factors enhancing seed longevity in tropical japonica rice. Curr. Plant Biol. 2021, 26, 100196.

23. Kameswara, R.N.; Jackson, M.T. Seed longevity of rice cultivars and strategies for their conservation in genebanks. Ann. Bot. 1996, 77, 251-260. [CrossRef]

24. Hay, F.R.; Timple, S.; van Duijn, B. Can chlorophyll fluorescence be used to determine the optimal time to harvest rice seeds for long-term genebank storage? Seed Sci. Res. 2015, 25, 321-334. [CrossRef] 
25. Lee, J.S.; Kwak, J.; Cho, J.H.; Chebotarov, D.; Yoon, M.R.; Lee, J.S.; Hamilton, R.S.; Hay, F.R. A high proportion of beta-tocopherol in vitamin $\mathrm{E}$ is associated with poor seed longevity in rice produced under temperate conditions. Plant Genet. Resour. 2019, 17, 375-378. [CrossRef]

26. Sasaki, K.; Takeuchi, Y.; Miura, K.; Yamaguchi, T.; Ando, T.; Ebitani, T.; Higashitani, A.; Yamaya, T.; Yano, M.; Sato, T. Fine mapping of a major quantitative trait locus, $q L G-9$, that controls seed longevity in rice (Oryza sativa L.). Theor. Appl. Genet. 2015, 128, 769-778. [CrossRef] [PubMed]

27. Wang, W.; Mauleon, R.; Hu, Z.; Chebotarov, D.; Tai, S.; Wu, Z.; Li, M.; Zheng, T.; Fuentes, R.; Zhang, F.; et al. Genomic variation in 3010 diverse accessions of Asian cultivated rice. Nature 2018, 557, 43-49. [CrossRef]

28. Lee, J.S.; Velasco-Punzalan, M.; Pacleb, M.; Valdez, R.; Kretzschmar, T.; McNally, K.L.; Ismail, A.M.; Cruz, P.C.S.; Hamilton, N.R.S.; Hay, F.R. Variation in seed longevity among diverse Indica rice varieties. Ann. Bot. 2019, 124, 447-460. [CrossRef]

29. Lee, J.S.; Kwak, J.; Hay, F.R. Genetic markers associated with seed longevity and vitamin E in diverse Aus rice varieties. Seed Sci. Res. 2020, 30, 133-141. [CrossRef]

30. Nakagomi, K.; Shigemune, A.; Sasahara, H.; Arai, T.; Hirabayashi, H.; Yamanouchi, U.; Ideta, O. Finding a novel QTL responsible for kernel cracking resistance from CSSLs of 'Itadaki' (O. sativa L.) $\times$ donor O. rufipogon. Breed. Sci. 2020, 70, 567-575. [CrossRef]

31. Arisaka, M. Analysis of factors that cause a high incidence of cracked rice kernel in Niigata prefecture in 2000. Hokuriku Crop Sci. 2002, 37, 52-53, (In Japanese with English summary).

32. Nitto, A.; Ito, O.; Agatsuma, Y. Primary factors of deterioration of rice quality in Miyagi prefecture in 1999 and 2000. Tohoku Agric. Res. 2001, 54, 35-36. (In Japanese)

33. Hayashi, T.; Kobayashi, A.; Tomita, K.; Shimizu, T. A quantitative trait locus associated with resistance to rice kernel cracking in progeny of japonica cultivars 'Nipponbare' and 'Yamahikari'. Hokuriku Crop Sci. 2017, 52, 67-70, (In Japanese with English summary).

34. Pinson, S.R.M.; Jia, Y.; Gibbons, J.W. Three quantitative trait loci conferring resistance to kernel fissuring in rice identified by selective genotyping in two tropical japonica populations. Crop Sci. 2013, 53, 2434-2443. [CrossRef]

35. Nakagomi, K.; Ideta, O.; Shigemune, A.; Ohta, H.; Kaji, R.; Fukushima, A.; Tsuda, N. QTL mapping of grain cracking resistance of rice derived from 'Yanxuan 203'. Breed. Res. 2014, 16, 122. (In Japanese) 